\title{
Chromosome 22 Deletions and Suicidal Behavior in Schizophrenia
}

\author{
Ali Bani-Fatemi ${ }^{\mathrm{a}}$ Christopher Adanty ${ }^{\mathrm{a}}$ Nasia Dai ${ }^{\mathrm{a}} \quad$ Ariel Graff $^{\mathrm{a}}$ \\ Philip Gerretsen ${ }^{a}$ Vincenzo De Luca ${ }^{a}$ b \\ ${ }^{a}$ Centre for Addiction and Mental Health, Toronto, ON, Canada; bepartment of Psychiatry, University of Toronto, \\ Toronto, ON, Canada
}

\section{Keywords}

Copy number variant $\cdot$ Suicide $\cdot$ Schizophrenia .

Chromosome 22

\begin{abstract}
Background: Studies have shown that the overall copy number variant (CNV) load is associated with schizophrenia. Schizophrenia is a mental disorder that is frequently associated with suicidal behavior. Methods: We recruited 263 patients with schizophrenia from the Centre for Addiction and Mental Health. The Columbia Suicide Severity Rating Scale was used to assess the presence of lifetime suicide attempt. Genotyping was completed using the Illumina Omni 2.5 chip. We tested the association between deletion events on chromosome 22 with suicide attempt in our schizophrenia sample. Results: There was no significant difference between suicide attempters and non-attempters considering the presence/absence of deletion events on chromosome 22. Conclusion: Although our results did not show a significant association between deletions on chromosome 22 and suicide attempt in schizophrenia, CNV studies may reveal important, novel insights and open further investigation for the treatment of neuropsychiatric diseases.
\end{abstract}

(c) 2021 The Author(s)

Published by S. Karger AG, Basel

karger@karger.com

www.karger.com/nps

Karger $\stackrel{\text { ' }}{5}$

bOPEN ACCESS
(C) 2021 The Author(s)

Published by S. Karger AG, Basel

This is an Open Access article licensed under the Creative Commons (http://www.karger.com/Services/OpenAccessLicense), applicable to the online version of the article only. Usage and distribution for commercial purposes requires written permission. Attribution-NonCommercial-4.0 International License (CC BY-NC)

\section{Introduction}

The suicide rate in patients with schizophrenia (SCZ) is approximately $5 \%$ [1]. In comparison, suicide attempts occur at a much higher rate, ranging from 30 and up to $49 \%$ in some studies [2-4]. Specifically, for SCZ, a shorter lifespan is partly attributable to elevated suicide rates [5]. Like the general population, the best predictors to identify individuals most at risk to commit suicide are those with a history of previous suicidal attempts [6-8]. Other known risk factors for suicide in SCZ include recent stressful life events [9] and specific personality traits such as alexithymia [10]. Although the anti-suicide effect of specific antipsychotics has been reported [11], analyzing DNA variations (e.g., SNPs, copy number variation $[\mathrm{CNV}]$, and epigenome modifications) is a promising method of identifying SCZ patients at heightened risk for suicide.

SCZ is a severe mental health disorder with high heritability. One important heritable factor believed to contribute to the development of SCZ is CNV [12]. CNVs are deletions or duplications of a segment of the genome usually $>1 \mathrm{~kb}$. Evidence suggests that copy number variants have a robust and reproducible impact on SCZ [13]. $22 \mathrm{q} 11.2$ deletion represents one of the greatest known genetic risk factors for the development of psychosis. Genes within the 22q11.2 locus have been implicated in the etiology of idiopathic psychosis [14].

Vincenzo De Luca

Centre for Addiction and Mental Health

250 College Street

Toronto, ON M5T 1R8 (Canada)

vincenzo.deluca@camh.ca 


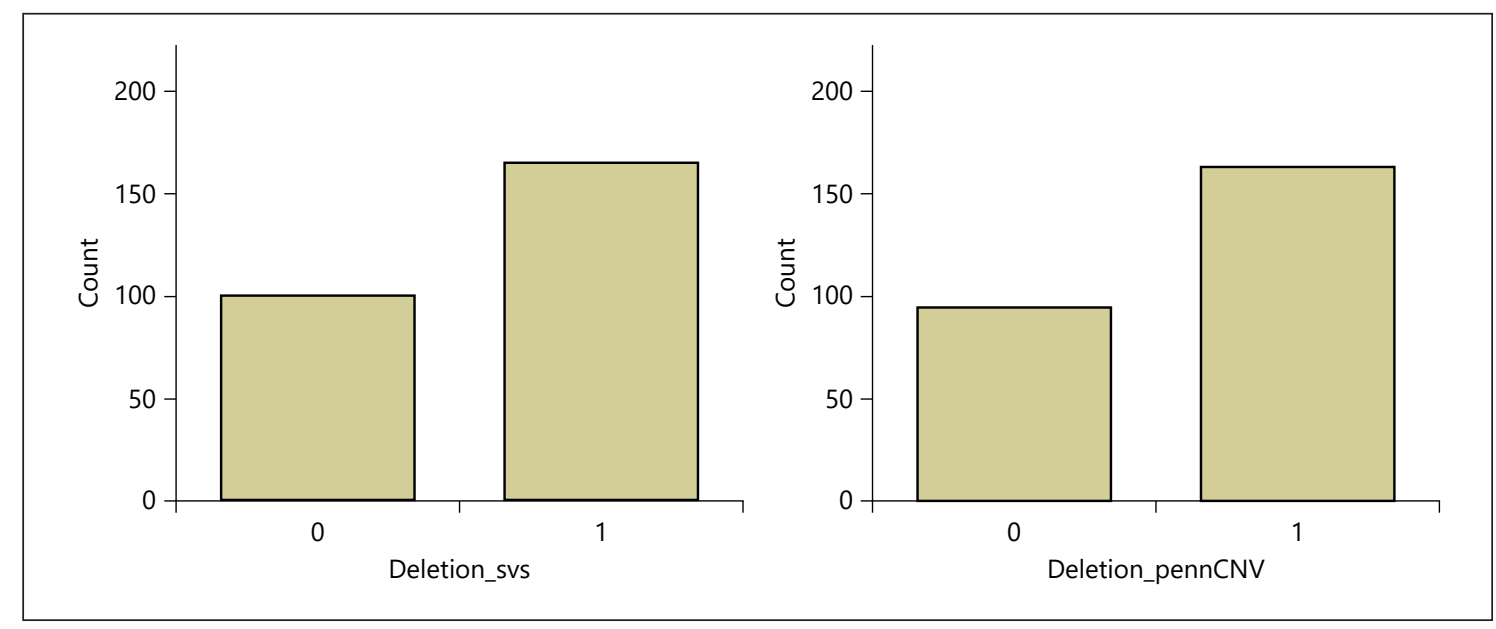

Fig. 1. Analysis of subjects with and without deletion events $(N=263)$. There were more subjects with deletions than without in both algorithms $(0=$ absence of deletion events; $1=$ presence of at least 1 deletion event $)$.

To date, nobody has tested the hypothesis that a larger number of CNVs could confer susceptibility for suicidal behavior in SCZ. Our hypothesis was that SCZ subjects with $\mathrm{CNV}$ deletions on chromosome 22 would demonstrate an increased risk for suicide attempt. Our specific aim was to analyze the impact of any chromosome 22 $\mathrm{CNV}$ deletion events in conferring risk for suicide attempt in our SCZ sample.

\section{Methods}

From the Centre for Addiction and Mental Health (CAMH) in Toronto (ON, Canada), 263 participants were recruited between the ages of 18 and 75 in a 5 -year period. Each subject selected was diagnosed with SCZ or schizoaffective disorder. From the recruitment, 101 were suicide attempters and 162 participants were nonattempters. The diagnosis of SCZ was confirmed using the Structured Clinical Interview for DSM-IV (SCID-I/P) [15]. The CAMH Research Ethics Board reviewed and approved the study. Written informed consent was obtained from all participating subjects. None of the participants was diagnosed with 22q11.2 microdeletion (velocraniofacial/DiGeorge syndrome). Determination of lifetime suicide attempts was conducted using gold-standard measures for the assessment of suicide behavior by the means of the Columbia Suicide Severity Rating Scale (C-SSRS) and the Beck Scale for Suicidal Ideation (BSS) [16, 17].

Genomic DNA was extracted from saliva or white blood cells using standard high-salt methods [18]. The Illumina Omni 2.5 chip was used to genotype $2.5 \mathrm{M}$ SNPs in our pilot sample. Log ratio values were calculated using the normalized intensity for each marker R using the software GenomeStudio.

The chromosome $22 \mathrm{CNV}$ analysis was performed using SNP and Variation Suite (SVS) version 8 (Golden Helix) implementing a segmentation-based algorithm [19]. A confirmation analysis was performed with PennCNV. PennCNV, which is a free software tool for CNV detection from SNP genotyping arrays, performs a hidden Markov model that integrates multiple sources of information to conclude CNV calls for individual genotyped samples [20]. However, Golden Helix SNP and Variation Suite (SVS) applies a segmentation algorithm using only the signal intensity data to detect CNVs on either a univariate or multivariate basis [21]. The univariate method considers only 1 sample at a time and was designed for detecting rare and/or large CNVs. However, the multivariate method considers all samples simultaneously and was designed for detecting small and common CNVs [19]. Both algorithms can handle the Illumina array.

In this study, suicide attempt lifetime was the main grouping variable. We used the number of deletion events on chromosome 22 as genetic predictors. Approximately 33,000 probes were used to scan chromosome 22 for CNV. SVS CNV analysis was performed using the univariate method considering only one sample at a time. We performed the SVS Copy Number Analysis Module (CNAM) segmenting algorithm to determine deletion events across chromosome 22. The array was run in duplicate for 4 subjects.

The nonparametric Mann-Whitney $U$ test was used to compare the total number of chromosome 22 deletions detected in suicide attempters and non-attempters. Presence and absence of deletion events were compared between suicide attempters and nonattempters by Pearson's $\chi^{2}$ test. The statistical analyses were performed using IBM SPSS Statistics version 24.

\section{Results}

We have analyzed 263 subjects with respect to the chromosome 22 deletions. We analyzed 4 subjects in duplicate to confirm the reliability of the deletion analysis. SVS CNV analysis showed 164 subjects with at least one 


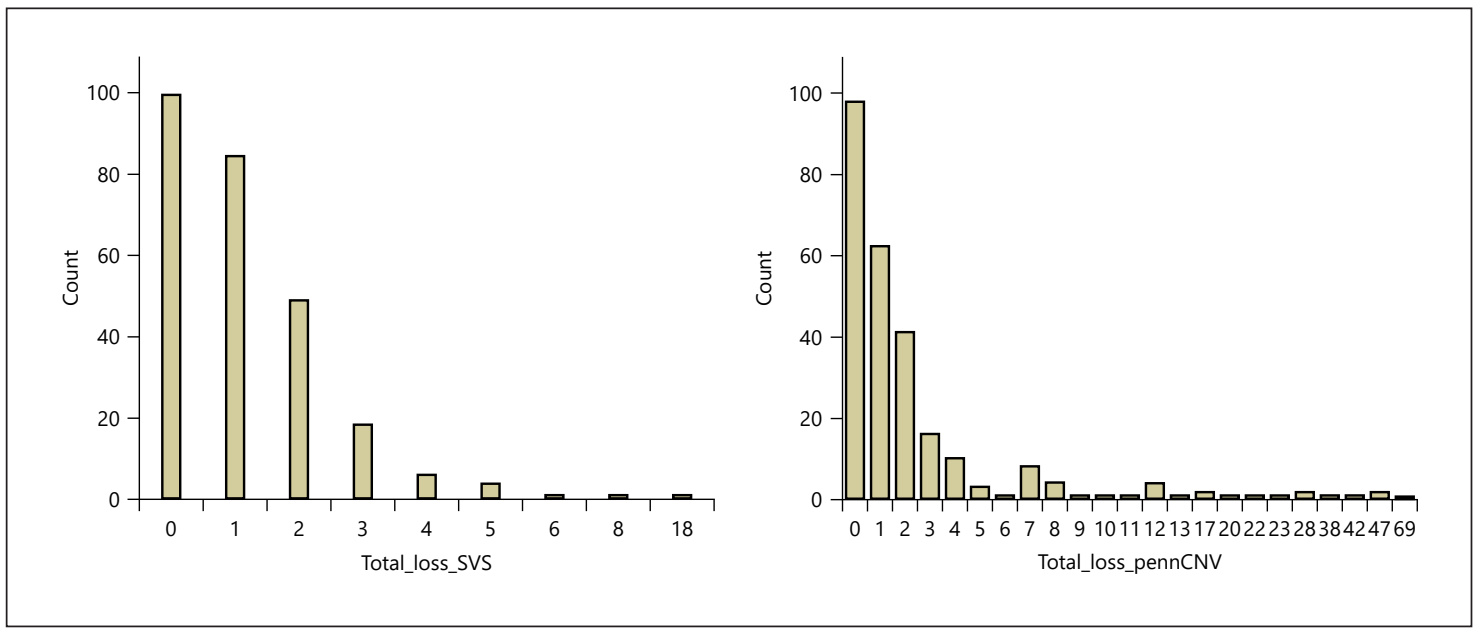

Fig. 2. The total number of deletion events using the CNAM analysis (SVS) and HMM model (PennCNV) in our sample $(N=263)$. There were more subjects with deletions than without. CNAM, Copy Number Analysis Module; HMM, hidden Markov model.

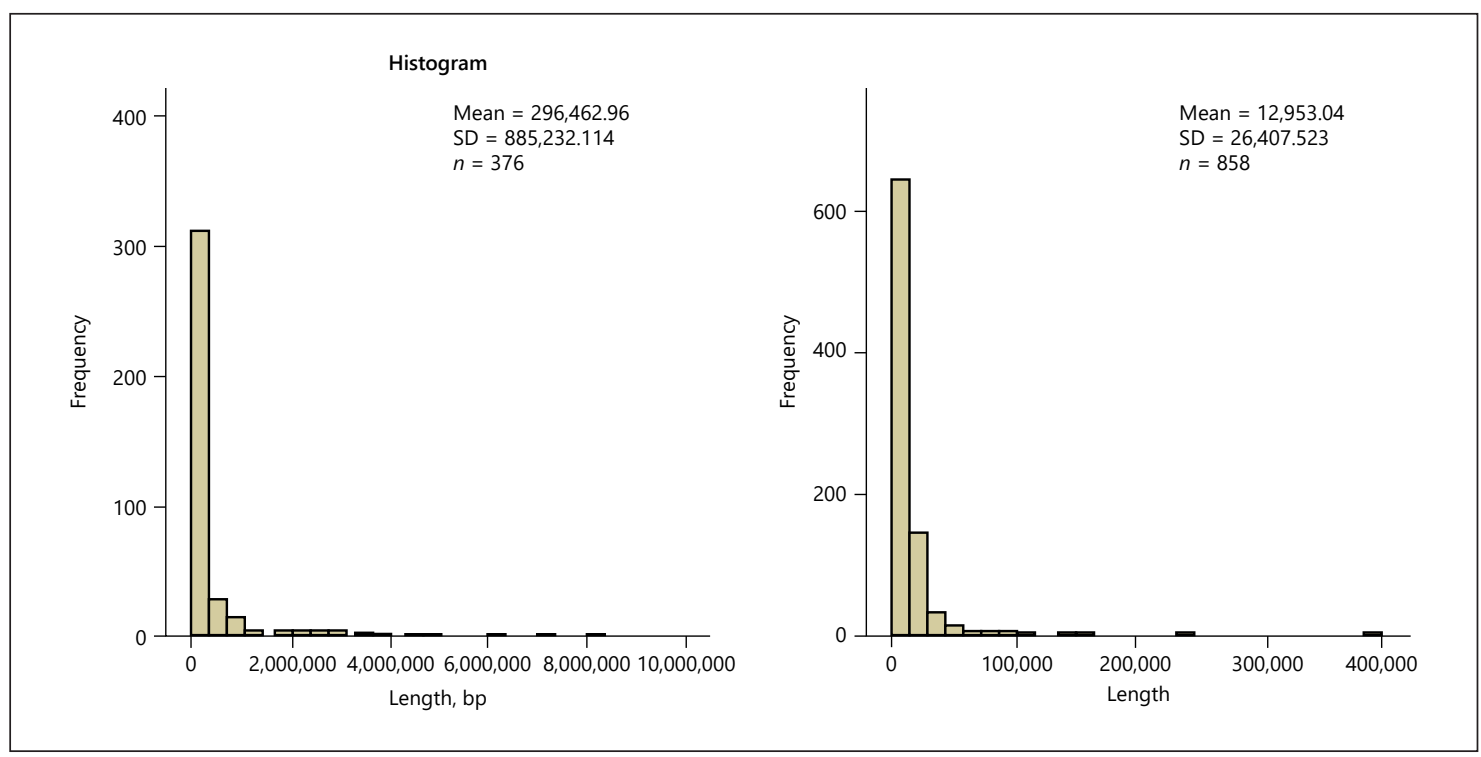

Fig. 3. Length distribution of deletions. Several large deletions were identified in SVS CNV analysis (left). PennCNV confirmed a few of the large deletion events (right).

deletion on chromosome 22, while the analysis with PennCNV results in 166 subjects with at least one deletion on chromosome 22 (Fig. 1). There were 99 subjects in SVS CNV analysis versus 97 subjects in the PennCNV analysis with no deletions on chromosome 22 (Fig. 1).

When we compared subjects with deletion and without deletion in suicide attempters and nonattempters, we found no significant difference $\left(\chi^{2}=0.03 ; 1 \mathrm{df}, p=0.42\right)$.
There were no differences between attempters and nonattempters in terms of number of deletion events using the Mann-Whitney $U$ test $(z=-0.327 ; p=0.744)$.

We also looked at the number of deletion for each subject. The maximum number of deletions per subjects detected by SVS was 18; however, the maximum number of deletions detected by PennCNV was 69 (Fig. 2). Although there were 80 subjects with a single deletion in SVS CNV 
analysis, the number of subjects with single deletion we found by PennCNV was 62. The distribution of the length of the deletions in the SVS CNV analysis indicated several large duplications; however, only a few of them were confirmed by PennCNV (Fig. 3). When we looked at the size of the deletion between attempters and nonattempt-

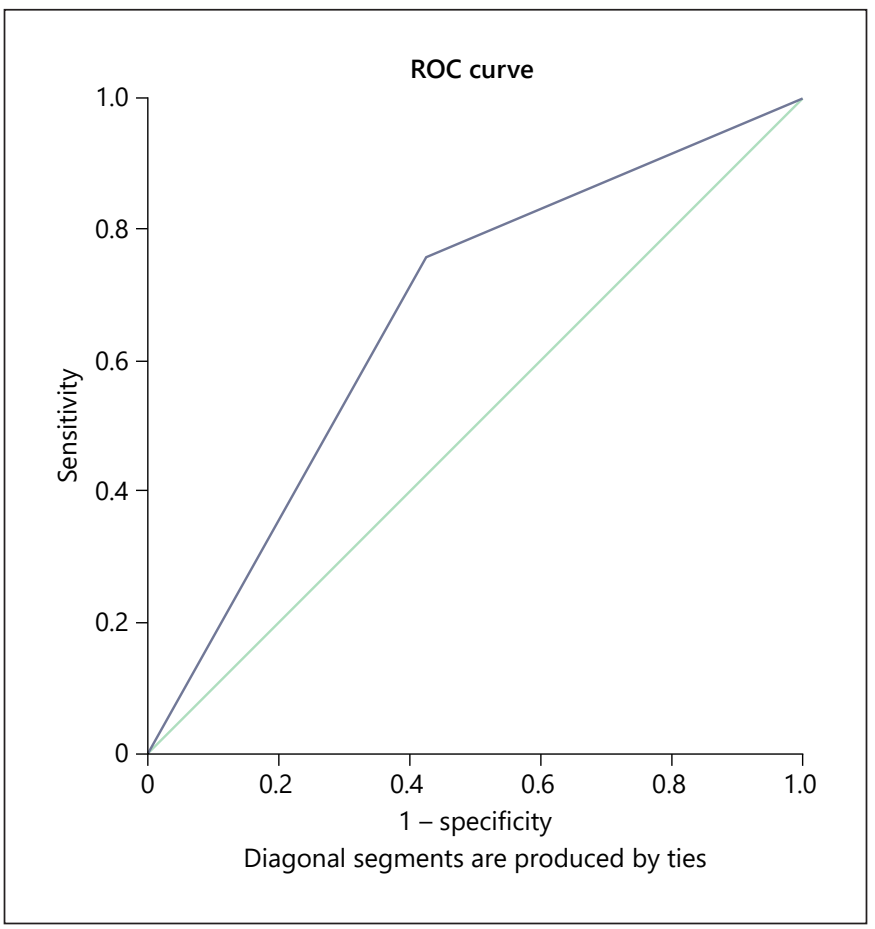

Fig. 4. ROC curve for deletion events detected by PennCNV and SVS. ROC, receiver operating characteristic. ers, we found no significant difference $(z=-0.570$; $p=$ $0.569)$. Figures $4-8$ show our $\mathrm{CNV}$ analysis in suicide attempters and nonattempters separately.

Tables 1 and 2 show the demographic characteristics of our sample. Age $(p=0.017)$, duration of illness $(p=$ $0.002)$, number of hospitalizations $(p=0.00005)$, and number of psychotic episodes $(p=0.0003)$ were significantly different between suicide attempters and non-attempters (Table 2). Among the clinical characteristics, only family history of suicidal behavior was significantly associated with suicide attempt (Table 3 ). We also analyzed the effect of several covariates on the number of deletion events. Our results suggest that the white European ethnicity has some effect on the number of deletions detected by both algorithms, SVS $(p=0.02)$ and PennCNV $(p=0.052)($ Table 4$)$.

Table 1. Difference between attempters and nonattempters

\begin{tabular}{|c|c|c|c|c|}
\hline \multirow[t]{3}{*}{ Characteristics } & \multicolumn{4}{|c|}{ Group } \\
\hline & \multicolumn{2}{|c|}{ nonattempters } & \multicolumn{2}{|c|}{ attempters } \\
\hline & $n$ & $\%$ & $n$ & $\%$ \\
\hline Total sample & 162 & 61.6 & 101 & 38.4 \\
\hline White European & & 84 & & 87.1 \\
\hline Female & & 30.9 & & 33.7 \\
\hline Employed & & 35.7 & & 30.4 \\
\hline Unemployed & & 60.7 & & 63.0 \\
\hline Retired & & 3.6 & & 6.5 \\
\hline Single & & 86.7 & & 73.6 \\
\hline Married & & 6.7 & & 13.2 \\
\hline Divorced & & 6.7 & & 13.2 \\
\hline
\end{tabular}

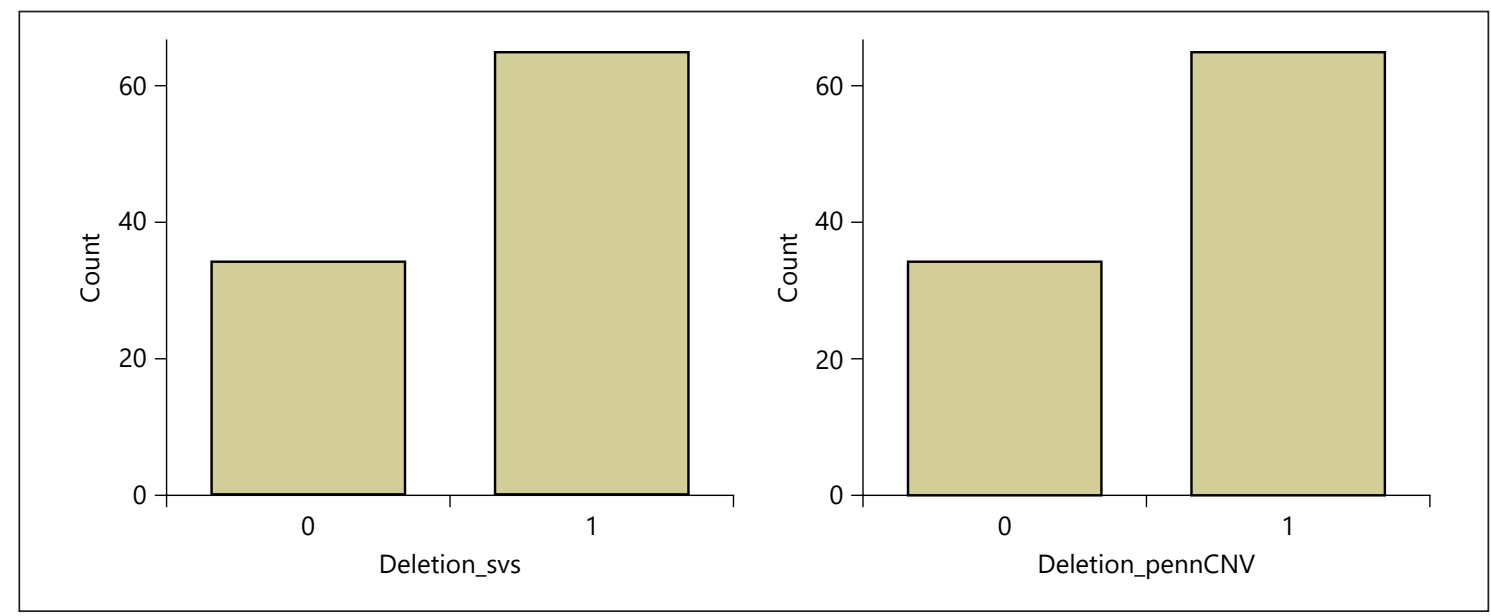

Fig. 5. Analysis of subjects with and without deletion events (suicide attempters $[n=101]$ ). 


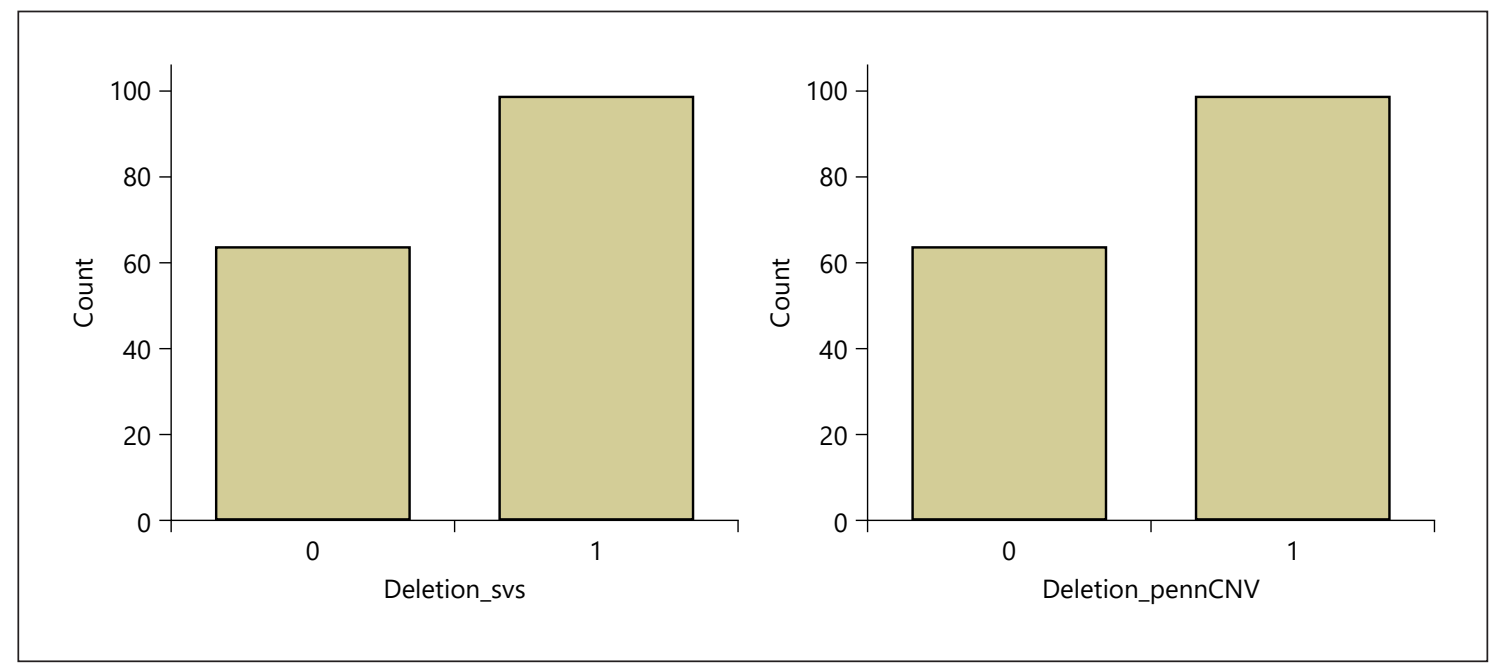

Fig. 6. Analysis of subjects with and without deletion events (nonattempters $[n=162]$ ).

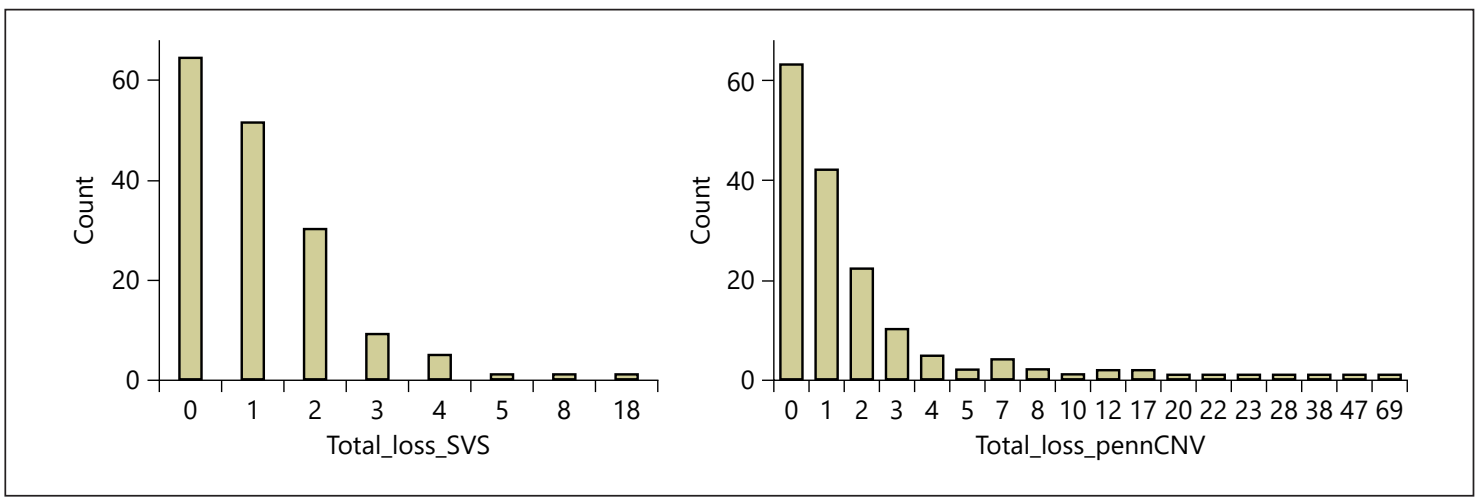

Fig. 7. Chromosome 22 deletions distribution in nonattempters $(n=162)$.

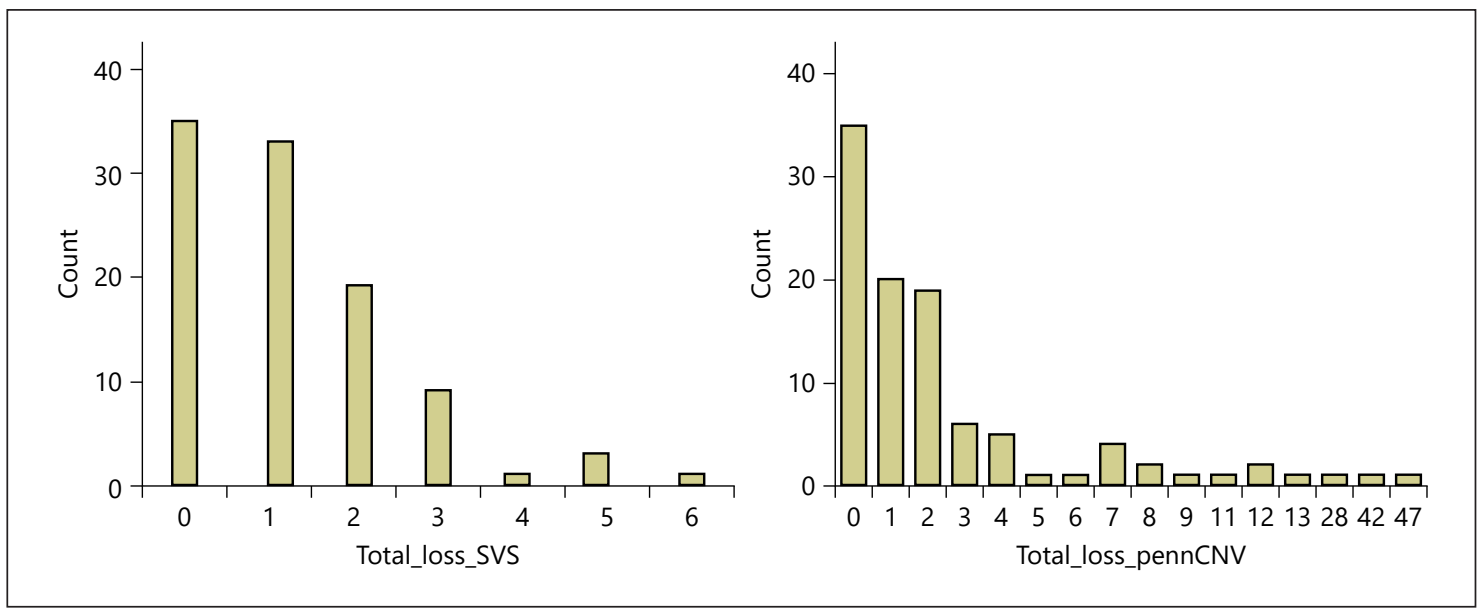

Fig. 8. Chromosome 22 deletion distribution in suicide attempters $(n=101)$. 
Table 2. Demographic characteristics

\begin{tabular}{|c|c|c|c|c|c|}
\hline & \multicolumn{2}{|c|}{ Suicide attempters } & \multicolumn{2}{|c|}{ Nonattempters } & \multirow[t]{2}{*}{$p$ value } \\
\hline & mean & SD & mean & SD & \\
\hline Age & 46.39 & 11.91 & 42.43 & 13.55 & 0.017 \\
\hline Age at onset & 21.80 & 7.32 & 23.39 & 7.82 & 0.102 \\
\hline Duration of illness, years & 23.71 & 12.65 & 18.78 & 12.73 & 0.002 \\
\hline Hospitalizations, $n$ & 7.29 & 6.67 & 4.24 & 4.98 & 0.00005 \\
\hline Psychotic episodes, $n$ & 8.54 & 11.50 & 4.53 & 4.89 & 0.0003 \\
\hline Duration of untreated psychosis, months & 24.27 & 57.81 & 30.46 & 73.08 & 0.486 \\
\hline
\end{tabular}

$\mathrm{SD}$, standard deviation.

Table 3. Clinical characteristics

\begin{tabular}{|c|c|c|c|c|c|}
\hline & \multicolumn{2}{|c|}{ Suicide attempters } & \multicolumn{2}{|c|}{ Nonattempters } & \multirow[t]{2}{*}{$p$ value } \\
\hline & $n$ & $\%$ & $n$ & $\%$ & \\
\hline Alcohol abuse & & 30 & & 34 & 0.139 \\
\hline Substance abuse & & 37.6 & & 28 & 0.118 \\
\hline Marijuana & & 22.5 & & 29.5 & 0.458 \\
\hline Smoker & & 44.6 & & 41.6 & 0.641 \\
\hline Cigarettes per day, $n$ & 9.5 & & 7.5 & & 0.193 \\
\hline Family history of suicide & & 34.4 & & 19.9 & 0.012 \\
\hline Family history of schizophrenia & & 41.9 & & 33.3 & 0.201 \\
\hline
\end{tabular}

Table 4. Effect of covariates on the number of deletion events

\begin{tabular}{lll}
\hline Variable & $\begin{array}{l}\text { Spearman's correlation } \\
p \text { value (SVS) }\end{array}$ & $\begin{array}{l}\text { Spearman's correlation } \\
p \text { value (PennCNV) }\end{array}$ \\
\hline Sex & 0.038 & 0.414 \\
Ethnicity & 0.024 & 0.053 \\
Age at onset & 0.841 & 0.565 \\
\hline
\end{tabular}

When we compared the analysis between SVS and PennCNV, we found inconsistent results. However, most of the deletions were detected by both methods; therefore, we reanalyzed our data with only those deletions that were detected by both algorithms. Using McNemar's test, 124 subjects with deletion events and 57 subjects without deletions were detected by both algorithms. To check the sensitivity and the specificity of our algorithms, we used the receiver operating characteristic (ROC) curve in SPSS. The area under the curve (AUC) was 0.666, and the sensitivity and specificity were 76 and $58 \%$, respectively, (Fig. 4).
PennCNV showed consistent results for 3 out of 4 subjects who were run in duplicate; however, the SVS results were consistent only for one of these subjects. With respect to the DNA extracted from saliva and blood samples, there were no differences in deletions between subjects.

\section{Discussion}

Copy number variants are deletions or duplications of a segment of DNA usually $>1 \mathrm{~kb}$. Evidence suggests that CNVs have a robust and reproducible impact on SCZ [13]. This study is the first CNV analysis that investigates chromosome 22 deletion events in suicide attempters with SCZ. With respect to suicidal behaviors, only 2 studies performed $\mathrm{CNV}$ analysis [22, 23]. However, these studies included mood disorder subjects in which the effect of CNVs is less evident than in SCZ. This specific $\mathrm{CNV}$ analysis of chromosome 22 does not show differences between suicide attempters and non-suicide attempters. 
In this study, SVS and PennCNV were used to investigate chromosome 22 deletion events to compare suicide attempters with SCZ and non-attempters with SCZ. Like other studies that have already described that CNV results differ depending on CNV detection methods, our $\mathrm{CNV}$ analysis from two different algorithms resulted in different findings $[24,25]$. From these results, it was identified that in some cases, they were consistent. We used 2 different algorithms as it has been recommended using multiple CNV calling algorithms rather than only one [24]. Using multiple CNV calling algorithms can decrease the false-negative results; however, it may also increase the false-positive findings. This heterogeneity in the results from different $\mathrm{CNV}$ calling algorithms highlights the necessity of standardizing array data collection, quality assessment, and experimental validation [21].

For this study, two limitations were identified. One limitation was due to the number of subjects recruited. With a small number of individuals studied, it is difficult to analyze rare CNVs. The second limitation identified was that the data used for this study were from different Illumina platforms (Omni 2.5 quad and eight). This may have resulted in different findings as the CNAM algorithm seems to overestimate the size of deletion events.

Future studies should investigate copy number variants in a larger sample of schizophrenic patients assessed for suicidal behavior. This is important as no studies have tested this specific hypothesis. 22q11.2 deletion represents one of the greatest known genetic risk factors for the development of psychosis. Genes within the 22q11.2 locus have been implicated in the etiology of psychosis [14]. Given the fact that genetic studies of suicide focused mainly on SNP analysis, we aimed to look at the effect of chromosome 22 deletions in conferring risk for suicide. The location of SNPs previously associated with suicidal behavior in psychiatric patients [26] did not coincide with CNVs we studied. Although in these preliminary data we have observed no direct CNV effect, there appears to be several confounding and experimental variables that influence deletion events and their detection. A study by Tombácz et al. [27] examined CNVs in the whole-exome sequencing of suicide victims with major depressive disorder finding no significant association.

Nevertheless, future studies may investigate CNVs in suicide attempt and ideation to determine whether the suicide phenotype is impacted by deletions and duplications across the entire genome. Moreover, since large $\mathrm{CNV}$ s in suicidal behavior are rare, future studies may use other techniques to increase the chance of detecting CNVs related to this phenotype [22].

\section{Statement of Ethics}

The study protocol was approved by the CAMH Institutional Research Ethics Board.

\section{Conflict of Interest Statement}

The authors declare no conflicts of interest.

\section{Funding Sources}

This project was supported by the American Foundation for Suicide Prevention (A.B.F.) and by the Miner's Lamp Award from the Department of Psychiatry at University of Toronto (V.D.L.). V.D.L. is recipient of a Scholar Award form the Department of Psychiatry, University of Toronto.

\section{Author Contributions}

Ali Bani-Fatemi analyzed the data and led the preparation of the manuscript. Vincenzo De Luca developed the study design, provided expert advice, and aided in manuscript revisions. The other authors helped with the data collection and the analysis.

\section{References}

1 Palmer BA, Pankratz VS, Bostwick JM. The lifetime risk of suicide in schizophrenia: a reexamination. Arch Gen Psychiatry. 2005; 62(3):247-53.

2 Montross LP, Kasckow J, Golshan S, Solorzano E, Lehman D, Zisook S. Suicidal ideation and suicide attempts among middle-aged and older patients with schizophrenia spectrum disorders and concurrent subsyndromal depression. J Nerv Ment Dis. 2008;196(12):88490.
3 Gupta S, Black DW, Arndt S, Hubbard WC, Andreasen NC. Factors associated with suicide attempts among patients with schizophrenia. Psychiatr Serv. 1998;49(10):1353-5.

4 Ran MS, Chen EY, Conwell Y, Chan CL, Yip PS, Xiang MZ, et al. Mortality in people with schizophrenia in rural China: 10-year cohort study. Br J Psychiatry. 2007;190:237-42.

5 Laursen TM, Nordentoft M, Mortensen PB. Excess early mortality in schizophrenia. Annu Rev Clin Psychol. 2014;10:425-48.
6 Wichstrøm L. Predictors of adolescent suicide attempts: a nationally representative longitudinal study of Norwegian adolescents. J Am Acad Child Adolesc Psychiatry. 2000; 39(5):603-10.

7 Sinclair JM, Mullee MA, King EA, Baldwin DS. Suicide in schizophrenia: a retrospective case-control study of 51 suicides. Schizophr Bull. 2004;30(4):803-11. 
8 Reutfors J, Brandt L, Jönsson EG, Ekbom A, Sparén P, Ösby U. Risk factors for suicide in schizophrenia: findings from a Swedish population-based case-control study. Schizophr Res. 2009;108(1-3):231-7.

9 Sher L, Kahn RS. Suicide in schizophrenia: an educational overview. Medicina. 2019;55(7): 361.

10 Marasco V, De Berardis D, Serroni N, Campanella $\mathrm{D}$, Acciavatti $\mathrm{T}$, Caltabiano $\mathrm{M}$, et al. [Alexithymia and suicide risk among patients with schizophrenia: preliminary findings of a cross-sectional study]. Riv Psichiatr. 2011; 46(1):31-7.

11 Orsolini L, Tomasetti C, Valchera A, Vecchiotti R, Matarazzo I, Vellante F, et al. An update of safety of clinically used atypical antipsychotics. Expert Opin Drug Saf. 2016; 15(10):1329-47.

12 Ahn K, Gotay N, Andersen TM, Anvari AA, Gochman P, Lee Y, et al. High rate of diseaserelated copy number variations in childhood onset schizophrenia. Mol Psychiatry. 2014; 19(5):568-72.

13 Sebat J, Lakshmi B, Malhotra D, Troge J, LeseMartin C, Walsh T, et al. Strong association of de novo copy number mutations with autism. Science. 2007;316(5823):445-9.

14 Williams HJ, Owen MJ, O’Donovan MC. Is COMT a susceptibility gene for schizophrenia? Schizophr Bull. 2007;33(3):635-41.
15 First MB. Structured clinical interview for the DSM-IV axis I disorders: SCID-I/P, version 2.0. New York, NY: Biometrics Research Department, New York State Psychiatric Institute; 1997.

16 Posner K, Brown GK, Stanley B, Brent DA, Yershova KV, Oquendo MA, et al. The ColumbiaSuicide Severity Rating Scale: initial validity and internal consistency findings from three multisite studies with adolescents and adults. Am J Psychiatry. 2011;168(12):1266-77.

17 Beck AT, Steer RA. Beck scale for suicide ideation (BSS). Bloomington, Indiana: Pearson; 1991.

18 Lahiri DK, Bye S, Nurnberger JI Jr, Hodes ME, Crisp M. A non-organic and non-enzymatic extraction method gives higher yields of genomic DNA from whole-blood samples than do nine other methods tested. J Biochem Biophys Methods. 1992;25(4):193-205.

19 SNP \& Variation Suite ${ }^{\mathrm{Tm}}$ (Version 8.x) [Software]. Bozeman, MT: Golden Helix, Inc. Available from: http://www.goldenhelix.com.

20 Wang K, Li M, Hadley D, Liu R, Glessner J, Grant S, et al. PennCNV: an integrated hidden Markov model designed for high-resolution copy number variation detection in whole-genome SNP genotyping data. Genome Res. 2017;17(11):1665-74.

21 Xu L, Hou Y, Bickhart DM, Song J, Liu GE. Comparative analysis of $\mathrm{CNV}$ calling algo- rithms: literature survey and a case study using bovine high-density SNP data. Microarrays. 2013;2(3):171-85.

22 Gross JA, Bureau A, Croteau J, Galfalvy H, Oquendo MA, Haghighi F, et al. A genomewide copy number variant study of suicidal behavior. PLoS One. 2015; 10(5):e0128369.

23 Perlis RH, Ruderfer D, Hamilton SP, Ernst C. Copy number variation in subjects with major depressive disorder who attempted suicide. PLoS One. 2012;7(9):e46315.

24 Winchester L, Yau C, Ragoussis J. Comparing CNV detection methods for SNP arrays. Brief Funct Genomic Proteomic. 2009;8(5):35366.

25 Pinto D, Darvishi K, Shi X, Rajan D, Rigler D, Fitzgerald $\mathrm{T}$, et al. Comprehensive assessment of array-based platforms and calling algorithms for detection of copy number variants. Nat Biotechnol. 2011;29(6):512-20.

26 Mullins N, Bigdeli TB, Børglum AD, Coleman JRI, Demontis D, Mehta D, et al. GWAS of suicide attempt in psychiatric disorders and association with major depression polygenic risk scores. Am J Psychiatry. 2019; 176(8):651-60.

27 Tombácz D, Maróti Z, Kalmár T, Csabai Z, Balázs Z, Takahashi S, et al. High-coverage whole-exome sequencing identifies candidate genes for suicide in victims with major depressive disorder. Sci Rep. 2017;7(1):7106. 